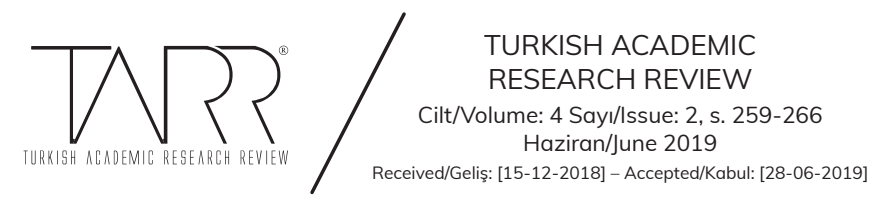

\title{
Kültürlerarası İletişimsel Yetinin Yabancı Dil Öğrenimindeki Yeri
}

Aykut Haldan ${ }^{1}$, Serap Pekbak ${ }^{2}$

\section{Öz}

Yabancı bir dil beraberinde her zaman yabancı bir kültürü de getirir. Bireylerin dili daha iyi anlayabilmeleri için dilini öğrendikleri ülkenin kültürel özelliklerini öğrenmeleri oldukça önemlidir. Kültür kavramı günümüz dünyası ve gelişen düşünce sistemi, ekonomik, politik ve sosyal gelişmelerin tamamını içerisine alan bir olgudur. Kültürlerarası iletişimsel yeti yabancı dil öğrenen her bireyde olması gereken bir edinimdir. Dil ve kültür edinci ayrılmaz bir bütündür. Gelişen ve değişen dünyada yabancı dil öğrenimin gerekliliği toplumlararası iletişimin vazgeçilmezidir. Dil öğrenimi sadece dil bilgisi kurallarını ve dilin yapısını öğrenmekle sağlanamaz, öğrenilen yabancı dilin de bir kültürden ortaya çıkmış olduğu unutulmamalıdır. Ana dilin kendine has bir kültürü olduğu gibi hedef dilin de kendine has kültür öğeleri mevcuttur. Kültürlerarası iletişimi sağlamak amacıyla yabancı dil öğretiminde kültürel öğelere olan gereksinim ön plana çıkmaktadır. Bir yabanc1 dilin öğrenilmesinde ve öğretilmesinde, kültürlerin anlaşılmasının ve kültürel öğelerin kullanımının yeri ve önemi büyüktür. Yabancı dil öğretiminde farklı kültürlerin farkında olmak ve onlarla ilişkili olmak, hedef dilin varlığının gelişmesinde ve zenginleşmesinde önemli bir rol oynamaktadır. Yabancı dil öğrenme isteği asıl nedenlerinden biride kişilerin yeni bir kültürü tanımaya ve öğrenmeye yönelmesidir. Yeni bir dil öğrenmek, yeni bir kültür edinmek kişiyi farklı dünyalara açılan pencereleri keşfetmesinde yarar sağlar. Bu çalışmada kültürlerarası yetinin yabancı dil öğrenimindeki yeri tartışılmış, kültür ve dil ilişkileri irdelenmiştir.

Anahtar Kelimeler: Kültürlerarası İletişimsel Yeti, Dil, Dil Edinci, Kültür

1 Dr. Öğr. Üyesi, Trakya Üniversitesi

Orcid ID https: //orcid. org/0000-0002-5852-3344

aykuthadan@trakya. edu. tr

2 Yüksek Lisans Öğrencisi Trakya Üniversitesi

serap.pekbak@gmail.com 


\title{
The Role of Intercultural Communication Faculty in Foreign Language Teaching
}

\begin{abstract}
A foreign language always brings with it a foreign culture. It is very important for individuals to learn the cultural characteristics of the country in which they learn the language in order to understand the language better. The concept of culture is a phenomenon that encompasses today's world and developing thought system, economic, political and social developments. Intercultural communicative competence is a must for every individual learning a foreign language. Language and culture acquisition is an integral whole. The necessity of foreign language learning in the developing and changing world is indispensable for inter-communal communication. Language learning cannot be provided only by learning the rules of grammar and the structure of the language, it should be remembered that the foreign language learned has emerged from a culture. As the native language has its own culture, the target language has its own cultural elements. In order to ensure intercultural communication, the need for cultural elements comes into prominence in foreign language teaching. Understanding and teaching of a foreign language is of great importance and place in the use of cultural elements. Being aware of and related to different cultures in foreign language teaching plays an important role in the development and enrichment of the existence of the target language. One of the main reasons for the desire to learn a foreign language is that people tend to recognize and learn a new culture. Learning a new language, acquiring a new culture helps one discover the windows of different worlds. In this study, the place of intercultural competence in foreign language learning is discussed and the relationship between culture and language is examined.
\end{abstract}

Keywords: Intercultural Communication Faculty, Language, Language Acquisition, Culture

\section{Giriş}

Yabancı dil eğitimi bölümlerinde öğrencilere kültür edincinin kazandırılması göz ardı edilemez. Yabancı dil öğrenen birey farklı bir kültürle karşı karşıyadır ve diğer kültürleri öğrenmeye açı olması gerekmektedir. Sadece eğitim bilimciler değil, aynı zamanda çeviribilimciler ve dilbilimciler de yabancı dil öğrenmenin amaçlarından birinin farklı kültürleri tanımak olduğunu hatta dil öğrenme sürecinde kazanılması gereken becerilerin en başında kültür edincinin sağlanması kanısındadırlar. Küreselleşen dünyada kültürlerarası yeti her bireyden beklenmektedir. Gelişen bilim ve teknoloji, iletişim ağının yaygınlaşması toplumların giderek yakınlaşmasına yol açmaktadır. Farklı kültürlere sahip olan insanlarla başarılı bir şekilde iletişime geçebilmek ve iletişimi sürdürebilmek için yabancı kültürün değerlerini, normlarını anlamak gerekmektedir. Yabancı dil derslerinde kültürlerarası yeti önemli role sahiptir. Dil ve kültür daima birbirlerini etkile-

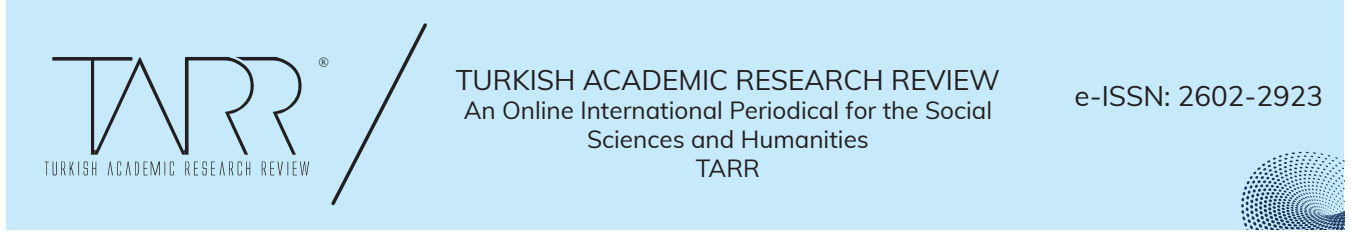


mektedir. Yabancı dil öğretiminin kültürden ayrı düşünülmesi imkânsızdır. Farklı kültürlerin iç içe yaşadığı, farklı dillerin aynı ortamda konuşulduğu günümüzde "kültürlerarası iletişimsel yeti" kavramı en dikkat çeken noktalardan biridir.

\section{Kültür Kavramı}

Kültür kavramını ele aldığımızda birçok alanda farklı anlamlar için kullanıldığını görmekteyiz. TDK'de Kültür kavramı için şu açılklamalar yapılmıştır; 1. Tarihsel, toplumsal gelişme süreci içinde yaratılan bütün maddi ve manevi değerler ile bunları yaratmada, sonraki nesillere iletmede kullanılan, insanın doğal ve toplumsal çevresine egemenliğinin ölçüsünü gösteren araçların bütünü, hars, ekin. 2. Bir topluma veya halk topluluğuna özgü düşünce ve sanat eserlerinin bütünü. 3. Muhakeme, zevk ve eleştirme yeteneklerinin öğrenim ve yaşantılar yoluyla geliştirilmiş olan biçimi. 4. Bireyin kazandığı bilgi. 5. Tarım. 6. Uygun biyolojik şartlarda bir mikrop türünü üretme.

Fazlasıyla geniş bir olguya sahip olan kültür sözcügüüü tanımlamak zordur. Kültür sözcüğü, ilk olarak Latince olan 'cultura' terimden meydana gelmiştir, aynı zamanda kökeni Almanca 'Kultur' kavramına da dayanmaktadır ve en temel anlamıyla; belirli dönemlerin, ülkelerin ya da toplulukların düşünsel ve yaşamsal özelliklerini kapsayan bir kavramdır. Toplumda şehirde yetişmiş, okumuş bilgili insanlara 'kültürlü' ve kırsalda yetişmiş sosyal aktivitesi olmayan gündelik yaşamla ilgisi ve bilgisi olmayan insanlara da 'kültürsüz' kavramını yakıştırırlar. Kültür kavramı aslında birden çok kelimeyle birlikte kullanılmaktadır, örneğin; yemek kültürü, tatil kültürü, sokak kültürü, vb. Bu anlamlar kişilerin yaşam şekillerine ve alışkanlıklarına göre değişir, herkesin kültürü kendine göre farklıdır ve birine göre kültürlüyken diğerine göre kültürsüz gelebilir;

"Kültür asla durağan değildir, kültürü yaşayan bir varlıktır ve insanların yaşamları sayesinde kendini sürekli geliştirmektedir. Kültür, insanı hayvandan ayıran, sadece insana has olan bir özelliktir. Kültür, insanlar tarafından paylaşılan ve gelecek kuşaklara intikal ettirilen bir semboller sistemidir (Erdentuğ, 1981: 35 Akt. Arslanoğlu).”

Kültür nesilden nesle aktarılır, insanların bir arada yaşamasını sağlayan ve kolaylaştıran kültürdür. İnsanlar sahip oldukları ve edindikleri bilgileri birbirleriyle paylaşırlar, aynı zamanda da bu bilgileri gelecek nesle de taşırlar. Kültür toplum içerisinde yeni nesillere aktarılarak varlığını sürdürür, yani kültür öğrenilerek süreklilik kazanır. Her ülkenin, her toplumun kendine has bir kültürü vardır. İnsanlar kendi kültürünü öğrenir ve o kültürü devam ettirirler. Bu yüzden her toplumun kültürü ve kültür anlayışı farklıdır;

"Toplumsal gelişmenin her aşamasının kendine özgü bir kültürü vardır. Ancak her toplumsal aşama kendi kültürünü oluştururken, geçmişin kültür mirasını devralır ve kendi kültürünü bunun üzerine kurar. Bir ülkede demokrasinin yerleşmesi için de toplumun belli bir kültür düzeyine ulaşması, çağdaş düşünceyi özümsemesi gerekmektedir (Gümüştekin. 317).”

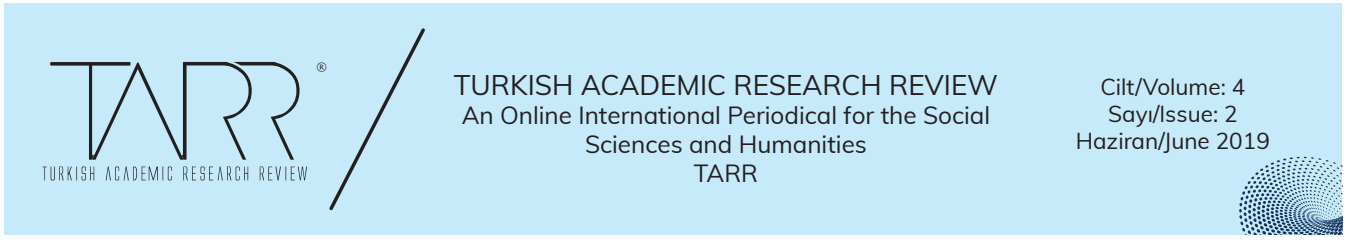




\section{Kültürlerarası İletişimsel Yeti}

Gaitanides'e (2003) göre "Bireyin kültürel arka planını bilmediğimiz sürece, kültürün de iletişimde ne kadar etkili olduğunu bilemeyiz" (Gaitanides, 2003: 48). Örnek olarak, gençlerin etnik özelliklerini ön plana çıkarmaları (Bommes, 1990: 25). Çok kültürlü toplumlarda, kültür bilgisinden çok bireysel yetenekler ve davranış beklentileri ön plana çıkmaktadır. "Kültürel sonuçlar bir hipotez içerisinde değerlendirilmelidir” (Gaitanides, 2003: 40). Örneğin bir kişi, yabanc1 bir kültür içerisinde yaşayabilir ve oradan kazandığı izlenimleri kendi ülkesinde yaşanılanlarla karşılaştırabilir. Edindiği tecrübeler sayesinde, belki yabancılara karşı olan olumsuz görüşlerini terk edebilir ve bu şekilde kültürlerarası yetisini geliştirebilir. Yabancı kültürlere olan hassaslaşmanın yanında iletişimde karşılıklı ilişkiler de önemlidir. Kültürlerarası yetiye sahip olan bir birey dil öğrenmek istediğinde bunu yapabilmesi için o dilin kültürünü de edinmesi gerektiğini bilir. Karşı tarafa duyulan empati veya o toplumun karşı tarafa olan ortak bakış açısı, toplumun göçmenler hakkındaki ortak düşünceleri ve değer yargıları, yabancılara karşı hassas davranma, özellikle önemlidir.

Tahsin Aktaş’a göre (2004: 46); iletişimsel yeti, "Bir dil toplumu ile iletişim kurmak için gerekli bilgilere ve bunların kullanılması için gerekli becerilere sahip olma anlamına gelmektedir. Başka bir deyişle dildeki göstergelerin değişik ortamlarda, yerinde ve zamanında anlamlı olarak kullanılmasını gerektirmektedir." Aktaş konu ile ilgili olarak bu yetinin yalnızca dil bilimsel ve toplum bilimsel iletişim ve etkileşim kurallarını değil, aynı zamanda iletişim olayları etkileşim işlemlerinin bağlam ve içeriğinin temelini oluşturan kültürel kuralları ve bilgileri de içerdiğini belirtmektedir Yabancı dil öğrenen birey farklı bir kültürle karşı karşıyadır ve diğer kültürleri öğrenmeye açıktır. Yani o dili öğrenebilmek için kültürünü de hayatına almalıdır. Her milletin kendine özgü atasözleri, deyimleri gelenek ve görenekleri bulunmaktadır. Aynı şekilde erek kültüründe kendine has kültür öğeleri ve değerleri vardır. Farklı bir kültürü öğrenmeden yabancı dil öğrenilemez. Teknoloji ve iletişim çağında farklı kültürleri öğrenmek artık daha kolaydır, çünkü farklı kültürleri yurtdışı seyahatlerine çıkarak, o kültür hakkında okuyarak veya o kültürden bireylerle arkadaşlıklar kurarak tanınabilir ve deneyimlenebilir. Öğrenciler öğrenmek istedikleri dilin kültürü dışında, ayıca genel bir kültüre de sahip olmalıdır. Kültür edincine sahip olan öğrenciler o dilin kullanımı açısından sorun yaşamazlar ve anlatılmak istenilenleri doğru anlamıla anlayabilirler.

\section{Dil ve Dil Yetisi}

Dil bir iletişim aracıdır demek, dilin birçok önemli özelliğini ve işlevini görmezden gelmek olur. "Dil, o dili konuşan toplumun kültürünü yansıtan bir ayna, o kültürün düşünüş biçimini, dünyayı algılayışını belirleyen belki de en önemli etken, toplum içi ve toplumlar arası ilişkilerin ön koşuludur” (Toklu 2003: 13). Dil, toplum içerisinde anlaşmayı sağlayan doğal bir araçtır. "Dil, ayrıca insanlar arasında karşılıklı haberleşme aracı olarak kullanılan; duygu, düşünce ve isteklerin: ses, şekil ve anlam bakımından her toplumun kendi değer yargılarına göre biçimlenmiş ortak kurallarının yardımı ile başkalarına aktarılmasını sağlayan, ses-

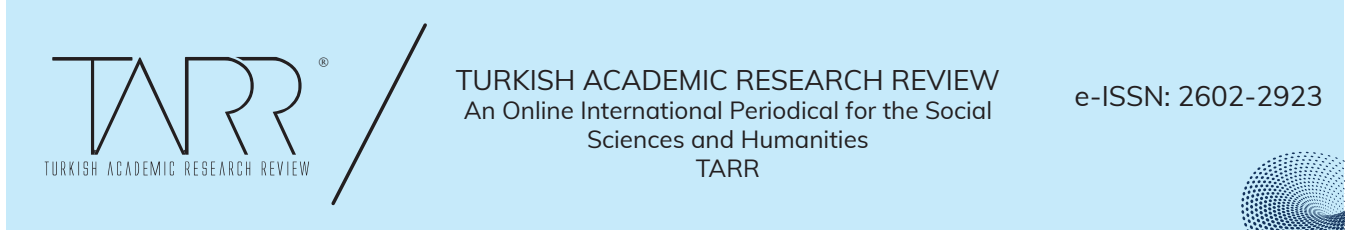


lerden örülü çok yönlü ve gelişmiş sistem olarak tanımlanır” (Korkmaz, 2007: $67)$. Bir sesli işaretler sistemi olan dil, aynı toplulukta yaşayan veya aynı milletten olan insanların anlaşabilmelerini sağlayan en gelişmiş iletişim aracıdır. Dil iletişim için kullanılır, bireyler günlük yaşantılarında birbirleriyle olan alışverişlerinde pek çok değişik amaçla dili kullanırlar.

Dili tanımak, dilin konuşulduğu toplumun yapısını, alışkanlıklarını, geleneklerini, coğrafi biçimini, sanat anlayışını, inançlarını, tarihini, en önemlisi de, dilin bir öğe olarak içinde bulunduğu kültürü tanımakla başlar. Çünkü her toplum birbirinden farklıdır ve buna bağlı olarak dil anlayışı da farklıdır. "Dil, toplumun bir yansımasıdır ve günlük hayatın alışılagelmiş olaylarında, bilimde, düşüncede, iletişimde, geleneklerde, sanatta, inançlarda, eğitimde, ekonomide, kısacası yaşamın her alanında bir koordinasyon oluşturarak toplumsal düzeni sağlamaktadır" (Dağabakan 2006: 210).

Dilin kaynağı çok eskilere dayanır ve dilin kendinden doğma kuralları vardır. Dil, toplumun ortaklaşa meydana getirdiği ve kullandığı canlı bir varlık, sosyal bir kurumdur. Dil, dilbilimciler tarafından, bir toplumu oluşturan kişilerin arasında karşılıklı haberleşme aracı olarak kullanılan düşünce ve duygularının, o toplumda ses, şekil ve anlam bakımından geçerli ortak ögeler ve kurallardan yararlanılarak başkalarına aktarılmasını sağlayan çok yönlü ve gelişmiş bir sistem aracı olarak tanımlanmıştır. Her dil, kendi kuralları içinde yaşayan ve gelişen canlı bir varlıktır. Aynı zamanda insanın iç dünyası ile dış dünyasını birbirine bağlayan en önemli araçtır. Dil, kuşaktan kuşağa aktarılabilen ve toplumun çeşitli özelliklerini yansıtan sosyal bir kurumdur, ayrıca kültürün koruyuculuğunu ve taşıyıcılığını yapan temel bir varliktır.

\section{Kültür - Dil İlişkisi}

Kültürün kendisi dil ile var olmaktadır. Yani, kültürün varlığını sürdürmesi, devamlılığını koruyabilmesi dil sayesinde olmaktadır. Dil ve kültür birbirini tamamlayıcı unsurlardır, Sıkı, dil ile kültür arasındaki etkileşimler üzerine şu saptamayı yapmaktadir:
"Kültürü oluşturan unsurlar söz konusu olduğunda karşımıza çıkan en önemli yapı taşlarından biri tartışmasız dildir. İnsanlığın başlangıcından beri toplulukların yaşamlarını sürdürmelerinde önemli bir yer tutmuş; in- sanoğlunun bilgi birikimini, mirasını gelecek kuşaklara aktarmada her daim önemli olmuştur. Neredeyse her topluluk kendi içinde iletişim kurabilmek için yeni bir dil geliştirmiş, bu diller de yine kendi içinde çeşitli değişiklik- lerle alt kültürleri temsil eder hale gelmiştir. Günümüzde bir kişinin hangi kültürden hatta hangi alt kültürden geldiğini ayırt etmede en belirgin özellik dildir. Böylelikle kendi bireyleri arasında iletişimi kuvvetlendirmiş ve kültü- rün de devamını sağlamıştır” (Sıkı, 2014: 11).

Dil bir kültürün öğesidir, bu bakımdan yabancı dil öğretiminde üzerinde durulması gereken önemli noktalardan biri de öğrencinin kültürel düzeyidir. Öğrenciler köy, kasaba veya şehir gibi farklı kültür gruplarından gelebilir. Öğrencilerin ait olduğu kültürün farkındalığı etkili ve sağlıklı bir yabancı dil öğretimi için

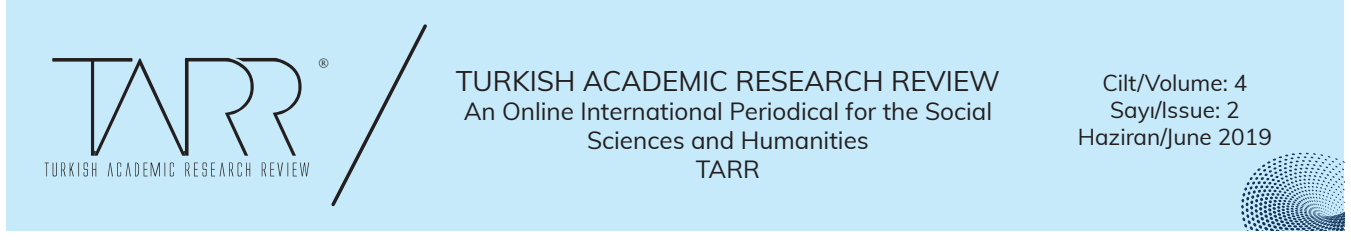


önemlidir. Öğrenci kültürünü bilmediği dilin terimlerini kavrayamaz. Örneğin köy kasaba gibi yerlerde yetişen öğrencilerin tropik meyve kavramını bilmeleri beklenemez. Bunun sebebi de bulundukları kültürde böyle bir meyvenin var olmayışıdır. Bir öğrenciye dil öğretmek için bunları göz önünde bulundurulmalıdır. Yani iyi ve kaliteli bir yabancı dil öğrenimi için kişinin belli bir kültür düzeyine varmış olması gerekiyor.

Diğer yandan öğrenci bir dili öğrenebilmek için o dilin kültürünü öğrenmeli ve en başta olmak üzere iletişim kurmalıdır. Kültürlerarası iletişim öğrenmenin en önemli unsurlardan biridir;

"Kültür, yalnızca dilsel yetiyi (competence linguistique) değil, aynı zamanda iletişimsel yetiyi (competence communicative) pekiştirir. İletişim kurmayan öğrenci, hangi yöntem uygulanırsa uygulansın, sistemden dışlanır, en azından dinamik bir unsur olmaktan çıkar. Oysa öğrenme her şeyden önce iletişim kurma ve dinamizm demektir. Bu ise, etkili bir mekanizmanın oluşmasıyla mümkündür." (Kayra, Aslan, 2013: 170).

Bir diğer önemli unsur ise öğrencinin nerede ve hangi ortamda dil öğrendiğidir. Öğrenci gerek anadilde gerekse yabancı dilde genel kültür bilgisini öğrenmelidir. Öğrenilecek olan dilin kültüründeki terimler ve ifadeler öğrenciye doğru biçimde verilmelidir. Yani kültürü oluşturan şey aslında bireylerin aralarındaki ilişki ve en önemlisi aralarındaki iletişimdir.

\section{Sonuç}

Kültür, insanların aileden başlayarak oluşturduğu bir kavram olarak düşünülebilir. Aile toplumun en küçük yapı taşıdır; örf, adet, gelenek ve görenekler gibi kültürü içine alan tüm kavramlar ailede başlayıp okulda devam eder. Okul ailenin çocuğa verdiği toplumsal gerçekleri yeniden biçimlendirir. Okul ailenin gücü ve kapasitesinin yetmediği, toplumsal gerçeklerin yeniden oluşturulduğu ve gerçekleştirildiği yerdir. Kısaca kültür her yaşın içinde bulunduğu bir öğedir. Okulun devreye girmesiyle birlikte yabancı dil öğrenme durumu da başlamış olur. Kültürü ortaya çıkaran, değiştiren, kültürü oluşturan öğelerden biri de bireylerin ilişkileri ve en önemlisi iletişimleridir. Yine kültürlerarası etkileşimi sağlayan da farklı kültürlerin iletişimidir. İletişim ancak dil sayesinde meydan gelir. Dil, kültür kavramının en destekleyici öğesidir. Kültür, dilin yardımı olmadan meydana gelmesi ve gelişmesi düşünülemez bir olgudur. Dil ve kültür birbirlerinden etkilenen ve etkileşimleri devam eden oluşumlardır. Kültür, toplumu oluşturan kişileri, onları bir arada tutan dil ve haberleşme süreçlerini, sanatlarını, inançlarını, törelerini, hukuk kurallarını da kapsamaktadır. İletişimin hızla gelişmesi sayesinde bilgiye daha çabuk ulaşabilen insanoğlu farklı kültürlere de daha hızlı ulaşabilmektedir. Dil ve kültürün birbirlerini etkileyip biçimlendirdikleri göz önüne alındığında yabancı dil öğretiminin kültürden ayrı düşünülmesi imkânsızdır.

Farklı kültürleri yurtdışı seyahatlerine çıkarak, o kültür hakkında okuyarak veya o kültürden bireylerle arkadaşlıklar kurarak tanıyabilir ve deneyimleyebiliriz. Farklı kültürleri tanımanın, kendi kültürümüzün tek ve en doğru, en iyi kültür ol-

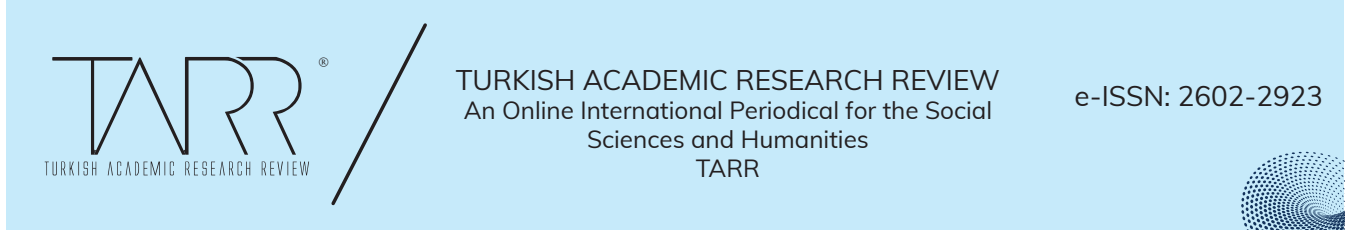


madığının, her kültürün kendi dinamikleri çerçevesinde değerlendirilmesi gerektiğinin farkına varmanın en uygun ortamlarından birisi de yabancı dil sınıflarıdır. Yabancı dil öğrenen birey farklı bir kültürle karşı karşıyadır ve diğer kültürleri öğrenmeye açıktır. Yenilikler daima insanı geliştirmektedir bilinmeyeni öğrenmek tanımak kişiyi sosyalde aktif tutar. Yabancı bir dil edinimi doğal olarak yabancı bir kültür edinimini beraberinde getirir. Ancak dil öğrenmeye bir bütün olarak bakıldığında kültürlerarası yetiye sahip olunur. Yani dili bir kurallar bütünü olarak değil, iletişim ve kültürün ayrılmaz olmadığını unutmamak gerekir.

\section{Kaynakça}

Aktaş, T. (2004). "Yabancı Dil Öğretiminde İletişimsel Yeti". Sosyal Bilimler Dergisi, Selçuk Üniversitesi, Konya, Sayı 12, s. 45-58.

Auernheimar, Georg (Hrsg.) (2002) "Interkulturelle Kompetenz und Professionalität, Opladen”.

Arslanoğlu, İbrahim: Kültür Ve Medeniyet Kavramlar http: //w3. gazi. edu. tr/ iarslan/ kulturvemedeniyet. pdf

Baykara, Bahri: (2010) "Yabancı Dil Eğitiminde Kültürlerarasılık" (Yüksek Lisans Tezi, Fırat Üniversitesi Sosyal Bilimler Enstitüsü Batı Dilleri ve Edebiyatları Anabilim Dalı İngiliz Dili ve Edebiyatı Bilim Dalı ELAZIĞ, 2010) Sayfa: IX, 158

Bommes, Manfred (1990) "Die meisten türkischen Väter sind so.", Informationsdienst zur Ausländerarbeit, H. 4.

Bingöl, Cevdet: (2010) "Kültürlerarası İletişim Sürecinde Kültür, Kültürel Kimlikler ve Çeviri İlişkisi” (Yüksek Lisans Tezi Muğla Üniversitesi Sosyal Bilimler Enstitüsü Mütercim Tercümanlık Anabilim Dalı, Haziran 2010, Muğla)

Dağabakan, Fatma Öztürk: (2006) İki Ayrı Kültür, İki Farklı Dil, A. Ü. Türkiyat Araştırmaları Enstitüsü Dergisi, Sayı 31, Erzurum, 2006, s. 209

Gaitanides, St. (2003) Ergebnisse der wissenschafliche Begleitung eines Projekts zur Einführung des Qualitätsmanagement in der interkulturellen Kinder-, Jugend- und Familienarbeit in München. In: Sozialreferat der Landeshauptstadt München (Hg.) Offen für Qualität. Interkulturell orientiertes Qualitätsmanagement in Einrichtung der Migrationssozialarbeit. München.

Gümüsstekin, Nuray: (2011) “Kültür” Kavramı Ve Osmanlı'dan Günümüze Kültürel Yapının İncelenmesi, Atatürk Kültür, Dil Ve Tarih Yüksek Kurumu 38. ICANAS (Uluslararası Asya ve Kuzey Afrika Çalışmaları Kongresi) 10-15. 09. 2007 Ankara / Türkiye, Bildiriler, Kültürel Değişim, Gelişim Ve Hareketlilik I. Cilt Ankara-2011: 317

Kayra, Erol - Aslan, Nuran: (2013) Yabancı Dil Öğretiminde Genel Kültür ve Çeviri Olgusu, Çukurova Üniversitesi Sosyal Bilimler Enstitüsü Dergisi Cilt 4, Sayı 4, Aralık 2013: 169

Korkmaz, Zeynep (2007), Gramer Terimleri Sözlüğü, TDK Yayınları, Ankara.

Sıkı, Elif: (2014) "Kişilerarası İletişim Bilim Dalı Yabancı Dil Öğretiminde Kültür Farkındalığı Yaratma Ve Kültürlerarası İletişim Becerilerinin Geliştirilmesi” (Yüksek Lisans Tezi, Marmara Üniversitesi Sosyal Bilimler Enstitüsü Halkla İlişkiler Ve Tanıtım Anabilim Dalı, İstanbul, 2014)

Toklu, Osman (2003), Dilbilime Giriş, Akçağ Yayınevi, Ankara.

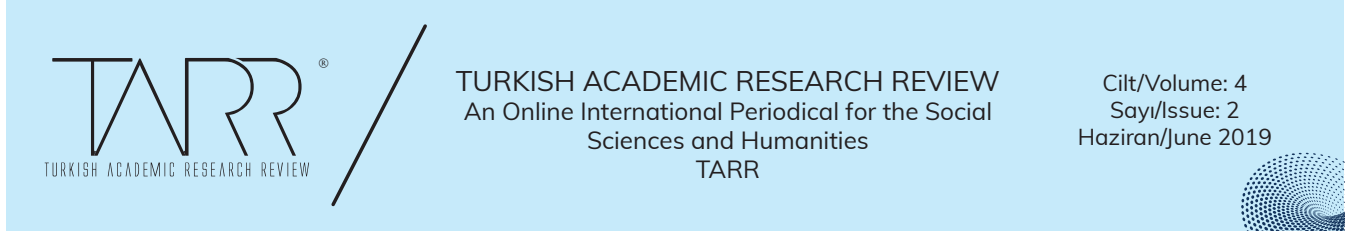


